June 1990

\title{
Psychodynamic Psychiatry in Clinical Practice
}

\author{
Edward Kim, M.D. \\ Thomas Jefferson University
}

Follow this and additional works at: https://jdc.jefferson.edu/jeffjpsychiatry

Part of the Psychiatry Commons

Let us know how access to this document benefits you

\section{Recommended Citation}

Kim, M.D., Edward (1990) "Psychodynamic Psychiatry in Clinical Practice," Jefferson Journal of Psychiatry. Vol. 8 : Iss. 2 , Article 14.

DOI: https://doi.org/10.29046/JJP.008.2.013

Available at: https://jdc.jefferson.edu/jeffjpsychiatry/vol8/iss2/14

This Article is brought to you for free and open access by the Jefferson Digital Commons. The Jefferson Digital Commons is a service of Thomas Jefferson University's Center for Teaching and Learning (CTL). The Commons is a showcase for Jefferson books and journals, peer-reviewed scholarly publications, unique historical collections from the University archives, and teaching tools. The Jefferson Digital Commons allows researchers and interested readers anywhere in the world to learn about and keep up to date with Jefferson scholarship. This article has been accepted for inclusion in Jefferson Journal of Psychiatry by an authorized administrator of the Jefferson Digital Commons. For more information, please contact: JeffersonDigitalCommons@jefferson.edu. 


\title{
Psychodynamic Psychiatry in Clinical Practice
}

\author{
Glen O. Gabbard, M.D. \\ American Psychiatric Press, 1990 \\ 480 pages \\ $\$ 49.95$ \\ Edward Kim, M.D.
}

The process of becoming a psychiatrist is growing ever more complex in this "Decade of the Brain." With increasingly powerful developments in neuroscience research, one might question the investment of time and effort necessary to understand psychodynamics. Why, then, did the American Psychiatric Press commission a major volume dealing with just this topic? Glen Gabbard addresses this question and its dualistic implications in the introduction and text of Psychodynamic Psychiatry in Clinical Practice. Rather than taking part in the sectarian debate between dynamic and biological psychiatrists, Dr. Gabbard, training and supervising analyst at the Topeka Institute for Psychoanalysis and director of the C. F. Menninger Memorial Hospital, elaborates on the practical application of dynamic theory to modern psychiatric practice. This integrative approach is especially helpful for residents developing the dual identity of psychotherapist and physician:

"The patient must be viewed simultaneously as a disturbed person and as a diseased central nervous system. The former view requires an empathic subjective approach, while the latter demands an objective medical model approach. The clinician must be able to shift between these two modes gracefully yet also stay attuned to the impact of the shift on the patient." (p. 126)

The book is divided into three sections. The first addresses basic dynamic principles and treatment modalities. The second discusses DSM-III-R Axis I disorders. The third covers Axis II disorders. The first chapter defines and explains basic dynamic principles such as transference, countertransference, psychic determinism, and the role of the unconscious. Chapter Two discusses three major psychoanalytic paradigms: ego psychology, object relations theory, and self psychology. It is evident from the volume and detail devoted to object relations that this is one of Dr. Gabbard's areas of particular expertise. The section on ego psychology was somewhat sparse but adequate for an introduction. I was disappointed by the absence of earlier psychoanalytic paradigms such 
as the libido and dual instinct theory. Although one might consider these to be outdated forerunners of modern ego psychology, they each contribute important aspects to our understanding of psychological development and psychopathology. In addition, inclusion of these theories would help clarify the development of all three later paradigms, since each attributes its origins to classical analytic theory. The subsequent chapters in Section One are an introductory overview on psychodynamic assessment and the different treatments which can be administered by a dynamically informed psychiatrist. These include brief and longterm individual, group, marital, family, and pharmacologic therapies. One of the highlights of the book is the chapter on dynamically informed hospital treatment. Dr. Gabbard elegantly presents hospital treatment as a milieu in which patients recreate a variety of object relations in a transferential pattern which, if managed properly, can be enormously therapeutic to otherwise treatment-resistant patients. His application of object relations theory to inpatient treatment is well worth the price of the book in that it challenges the notion that inpatient psychiatry is largely a task of managing behavior while waiting for somatic treatments to take effect. With the exception of Oldham and Russakoff's work (1), there have been few recent major publications so helpful in clarifying the dynamic treatment of hospitalized patients.

Section Two introduces us to the rich psychoanalytic tradition as applied to the neuroses and psychoses currently listed under Axis I of the DSM-III-R. Dr. Gabbard discusses the potential meaning underlying symptoms such as hallucinations, delusions, anxiety, and substance abuse. He does not ignore the literature on biological psychiatry, opting instead to integrate current findings with dynamic principles. Dr. Gabbard is not ashamed to acknowledge the limitations of psychotherapeutic (and even psychodynamic) interventions in the treatment of these disorders; rather, he expands the available armamentarium of psychiatrists to include interventions and approaches which may enhance the efficacy of biological treatments.

Section Three is devoted to the personality disorders, a topic of much debate both diagnostically and therapeutically in the psychoanalytic and general psychiatric communities. The literature supporting different descriptive and dynamic classifications is extensively reviewed; critiques of these approaches and the current DSM-III-R nosology are presented. However, the heavy emphasis on object relations theory tends to obscure the dynamic differences between some of the more primitive personality disorders, i.e., borderline, schizoid, schizotypal, and paranoid. The use of primitive defenses such as projective identification and splitting is common to several of the disorders and is subsumed under Kernberg's broad rubric of borderline personality organization. Nevertheless, Dr. Gabbard's presentation is helpful in the identification and management of generalized countertransference responses to these defenses. A particular strength was the distinction between high- and low-functioning histrionic personality disorders. Using the traditional "hysterical personality" for the former, Gabbard distinguishes dynamic, descriptive and developmental differ- 
ences between the two. Although hysterical personality disorder is not in the DSM-III-R, this classification is valuable both heuristically and therapeutically. Similar comparisons are made between schizoid and schizotypal, and narcissistic and antisocial personality disorders.

Psychodynamic Psychiatry in Clinical Practice is an excellent introduction to dynamics in modern psychiatry, reminiscent of John Nemiah's classic, Foundations of Psychopathology (2). Its clarity and organization make it accessible to residents at the PGY-2 or PGY-3 level. The decision of the American Psychiatric Press to commission a major work on dynamic psychiatry was bold but wellinformed. As the current enthusiasm for biological research and treatment yields to frustration with treatment-resistant patients, modern psychiatrists may seek a more human understanding of the individuals they treat. While this in itself may be of only limited therapeutic value to some patients, we cannot overlook the importance of such understanding to the physician engaged in a difficult and taxing profession.

\section{REFERENCES}

1. Oldham JM, Russakoff LM: Dynamic therapy in brief hospitalization. Northvale, NJ, Jason Aronson, 1986.

2. Nemiah JM: Foundations of psychopathology. New York, Oxford University Press, 1961. 